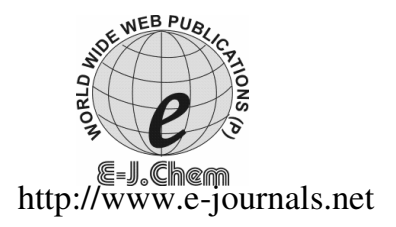

ISSN: 0973-4945; CODEN ECJHAO

E-Journal of Chemistry

2011, 8(1), 453-456

\title{
A Validated RP-HPLC Method for the Determination of Atazanavir in Pharmaceutical Dosage Form
}

\author{
K.SRINIVASU ${ }^{\S}$, J.VENKATESWARA RAO*, \\ N.APPALA RAJU and K.MUKKANTI ${ }^{\#}$ \\ Department of Pharmaceutical Chemistry, Sultan-Ul-Uloom College of Pharmacy \\ Mount Pleasant, Road No. 3, Banjara Hills, Hyderabad-500 034, India \\ ${ }^{\#}$ Center for pharmaceutical sciences, JNT University, Hyderabad, India \\ ${ }^{\S}$ ARD, Reddy Labs, Hyderabad, India \\ drjvrao9@gmail.com
}

Received 5 October 2009; Revised 27 March 2010; Accepted 20 May 2010

\begin{abstract}
A validated RP HPLC method for the estimation of atazanavir in capsule dosage form on YMC ODS $150 \times 4.6 \mathrm{~mm}, 5 \mu$ column using mobile phase composition of ammonium dihydrogen phosphate buffer $(\mathrm{pH} 2.5)$ with acetonitrile $(55: 45 \mathrm{v} / \mathrm{v})$. Flow rate was maintained at $1.5 \mathrm{~mL} / \mathrm{min}$ with $288 \mathrm{~nm}$ UV detection. The retention time obtained for atazanavir was at $4.7 \mathrm{~min}$. The detector response was linear in the concentration range of $30-600 \mu \mathrm{g} / \mathrm{mL}$. This method has been validated and shown to be specific, sensitive, precise, linear, accurate, rugged, robust and fast. Hence, this method can be applied for routine quality control of atazanavir in capsule dosage forms as well as in bulk drug.
\end{abstract}

Keywords: Atazanavir, Reverse phase high performance liquid chromatography, Atavir® capsules.

\section{Introduction}

Atazanavir is a orally administered chemotherapeutic agent used in the treatment of acute and chronic HIV infection (HIV protease inhibitor) with a chemical ${ }^{1}$ name 2,5,6,10,13pentaazatetradecanedioicacid,3-12-bis(1,1-dimethylethyl)-8-hydroxy-4,11-dioxo-9-(phenylmethyl)6-[-4-(2-pyridinyl)phenyl]methyl]-,dimethylester, $(3 S, 8 S, 9 S, 12 S)$ sulfate. Literature survey reveals few chromatographic methods for the determination of atazanavir in combination with other retroviral drugs in biological fluids ${ }^{2-8}$ and one assay with quantification of impurities method in active pharmaceutical ingredient ${ }^{9}$. The present paper aims at reporting sensitive, selective, precise, accurate, robust and rugged isocratic validated RP-HPLC method for the estimation of atazanavir in bulk as well as capsules dosage form. 


\section{Experimental}

Shimadzu HPLC with DAD detector was used with LC solution software. Milli-Q water, HPLC grade methanol and acetonitrile (Rankem Ltd) and GR grade ammonium dihydrogen phosphate and orthrophosphoric acid were used. The capsule formulation containing equivalent of $300 \mathrm{mg}$ of atazanavir (Atavir ${ }^{\circledR}-300 \mathrm{mg}$, Cipla) was procured from local market.

\section{Chromatographic conditions}

Chromatographic separation was achieved on YMC ODS (150 x $4.6 \mathrm{~mm}$ i.d. $5 \mu)$ analytical column at ambient temperature with mobile phase consisting of $2.0 \mathrm{~g}$ of ammonium dihydrogen phosphate in $1000 \mathrm{~mL}$ of Milli-Q water, adjusted $\mathrm{pH}$ to 2.5 with orthophosphoric acid and acetonitrile $(55: 45 \mathrm{v} / \mathrm{v})$. The flow rate was maintained at $1.5 \mathrm{~mL} / \mathrm{min}$ with injection volume $10 \mu \mathrm{L}$ and the detection was made at $288 \mathrm{~nm}$. Diluent was prepared by mixing $600 \mathrm{~mL}$ of methanol with $400 \mathrm{~mL}$ of buffer.

\section{Preparation of standard solution}

Accurately weighed $34 \mathrm{mg}$ of atazanavir sulphate standard into a $100 \mathrm{~mL}$ volumetric flask added about $60 \mathrm{~mL}$ of diluent and sonicated to dissolve and then made up to the volume with diluent to get $300 \mu \mathrm{g} / \mathrm{mL}$ standard solution.

\section{Preparation of sample solution}

Contents of 20 capsules weighed and mixed and equivalent to $30 \mathrm{mg}$ of atazanavir was taken into $100 \mathrm{~mL}$ volumetric flask, about $75 \mathrm{~mL}$ of diluent was added sonicated for $25 \mathrm{~min}$ at room temperature with intermediate shaking and then made up to volume with diluent. The sample solution was centrifuged at $7500 \mathrm{rpm}$ for $5 \mathrm{~min}$ to get a clear solution to get a concentration of $300 \mu \mathrm{g} / \mathrm{mL}$.

\section{Assay}

Sample solution of $10 \mu \mathrm{L}$ was injected into HPLC $(n=6)$ and recorded the chromatograph. The amount of drug present per capsule was calculated by comparing the peak area of the sample solution with that of the standard solution. Ruggedness of the method was checked on different days on different system following the proposed procedure. The data presented in Table 1.

Table 1. Results in assay

\begin{tabular}{cccc}
\hline & \multicolumn{3}{c}{ *Assay } \\
\cline { 2 - 4 } Parameter & Amount Claim, & \multicolumn{2}{c}{ Amount Found, mg/Capsule } \\
\cline { 3 - 4 } & mg/Capsule & Method Precision & Ruggedness \\
\hline Found, mg & & 299.71 & 299.15 \\
\% Assay & \multirow{2}{*}{300} & 99.9 & 99.7 \\
SD & & 0.23 & 0.18 \\
\% RSD & & 0.2 & 0.2 \\
\hline
\end{tabular}

${ }^{*}$ Assay average of six determinations $(n=6)$

\section{Linearity}

Several aliquots of standard stock solution $(1 \mathrm{~mL}=2600 \mu \mathrm{g} / \mathrm{mL})$ of atazanavir were taken in different $25 \mathrm{~mL}$ volumetric flasks and diluted up to the mark with diluent to obtained concentration of $30,60,150,210,300,360,455$ and $600 \mu \mathrm{g} / \mathrm{mL}$ of atazanavir. Peak areas were recorded for all the peaks and a calibration curve was obtained by plotting peak areas versus concentrations of atazanavir (Figure 1). 


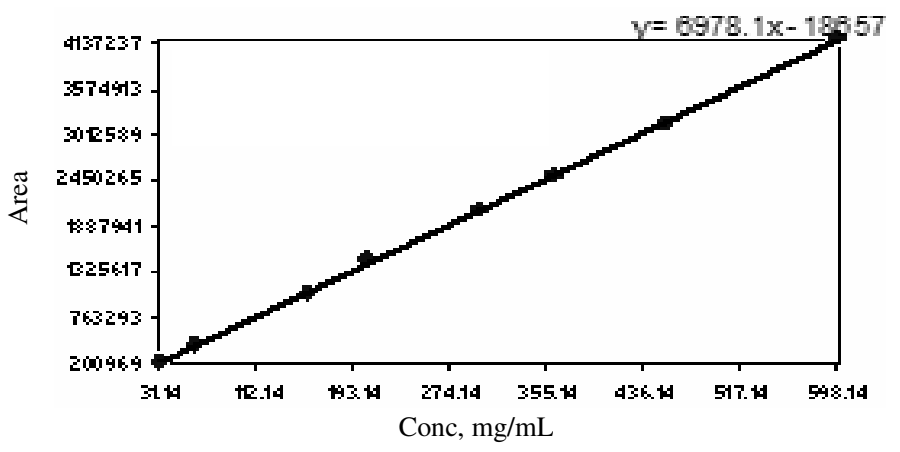

\section{Recovery studies}

Figure 1. Calibration curve of atazanavir by HPLC

Accuracy was determined by spiking the known amount of atazanavir drug substance to the pre analyzed samples and subjected to the proposed HPLC Method. The study was done at $20 \%, 50 \%$ and $150 \%$ of test concentration levels (i.e. 6,15 and $45 \mathrm{mg}$ respectively) in triplicates. Results of recovery study are shown in Table 2.

Table 2. Results of recovery studies.

\begin{tabular}{ccccccc}
\hline \multicolumn{9}{c}{ Accuracy } \\
\hline Sample ID & \multicolumn{3}{c}{ Amount Added, mg } & \multicolumn{3}{c}{ Amount Found, mg } \\
1 & 6.05 & 15.10 & 45.68 & 6.02 & 15.08 & 45.78 \\
2 & 6.05 & 15.05 & 45.50 & 5.99 & 15.07 & 45.73 \\
3 & 6.02 & 15.10 & 45.61 & 6.00 & 15.13 & 45.72 \\
\hline \multicolumn{3}{c}{$* *$ Accuracy performed in triplicates }
\end{tabular}

\section{Forced degradation}

Degradation studies are performed on drug product under acidic, alkali, oxidative, thermal and photolytic stress conditions. Each stress condition samples are analyzed in the proposed method and peak purity data is recorded to check the homogeneous nature of the drug.

\section{Robustness}

Standard solution was prepared and injected into HPLC following the proposed method in different variable conditions such as Flow $( \pm 10 \%)$, $\mathrm{pH}$ ( \pm 0.2 units), wavelength $( \pm 5 \mathrm{~nm})$ and organic composition in mobile phase $( \pm 2 \%$ absolute) and checked system suitability criteria in the each variable condition.

\section{Results and Discussion}

Atazanavir was freely soluble in methanol and has $\lambda_{\max }$ at $288 \mathrm{~nm}$, shown in Figure 2. System suitability parameters were carried out on freshly prepared standard stock solution of atazanavir as per the USP-XXVIII and reported in Table 3. Retention time achieved at $4.7 \mathrm{~min}$. Regression equation $\mathrm{y}=6978.1 \mathrm{x}-18657$ with concentration range of $30-600 \mu \mathrm{g} / \mathrm{mL}$ and the correlation coefficient $(\mathrm{r}=0.9999)$ obtained for atazanavir shows that the method is Linear. The assay results $(n=6)$ of atazanavir in capsules were found to be $99.9 \%$ for method precision, $99.7 \%$ for ruggedness and $99.9 \%$ for recovery studies. System suitability parameters are within the acceptance criteria in robustness study indicates the method is robust. All the stress condition samples were analyzed for $30 \mathrm{~min}$ and checked for co elution - peak purity passes in each stress condition indicates there is no co-elution with the main analyte. Above parameters demonstrates that the developed HPLC method was specific, fast, simple, precise, accurate, sensitive, linear, accurate, robust and rugged. Thus the developed method can be easily used for the routine quality control of bulk and capsule dosage form of atazanavir within a short analysis time. 


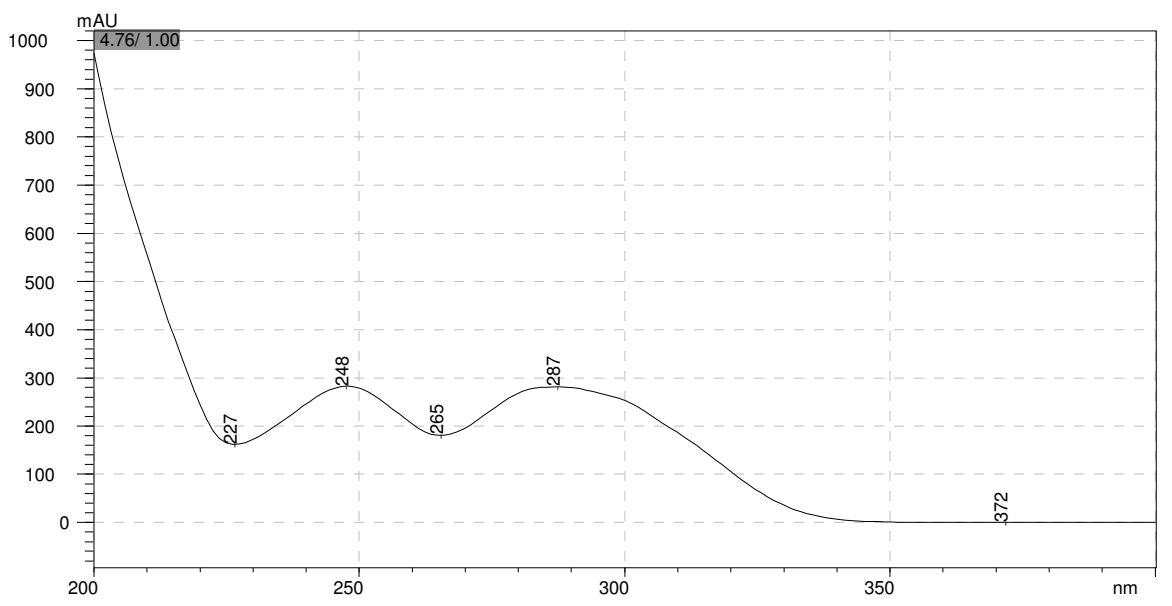

Figure 2. Spectrum of atazanavir standard by HPLC

Table 3. Validation and system suitability parameters

\begin{tabular}{lc}
\hline \multicolumn{1}{c}{ Parameter } & Atazanavir \\
\hline Retention time, min & 4.7 \\
Asymmetry & 1.1 \\
Theoretical plates & 7929 \\
Capacity factor & 4.0 \\
Minimum peak purity index & 10 \\
Wavelength, nm & 288 \\
Calibration range, $\mu \mathrm{g} / \mathrm{mL}$ & $30-600$ \\
Correlation coefficient & 0.9999 \\
Regression coefficient & 0.9998 \\
$\%$ RSD of standard & 0.1 \\
\hline
\end{tabular}

\section{References}

1. The Merck Index, XIV Edition, 142, 2008.

2. Cateau E, Tournier N, Dupuis A, Gwenael Le M and Venisse N, J Pharm Biomed Anal., 2005, 39(3-4), 791-795.

3. Loregian A, Pagni S, Ballarin E, Sinigalia E and Saverio G P and Palu G, J Pharm Biomed Anal., 2006, 42(4), 500-505.

4. Choi S Ok, Rezk N L and Kashuba Angela D M, J Pharm Biomed Anal., 2007, 43(4), 1562-1567.

5. Rebiere H, Mazel B, Civade C and Bonnet Pierre-Antoine, J Chromatography B, 2007, 850(1-2), 376-383.

6. Weller Dennis R, Brundage Richard C, Balfour Henry H and Vezina Heather E, $J$ Chromatography B, 2007, 848(2), 369-373.

7. D'Avolio A, Siccardi M, Sciandra M, Lorena B, Bonora S, Trentini L and Di Perri G, J Chromatogr B, 2007, 859(2), 234-240.

8. Cattaneo D, Maggiolo F, Ripamonti D and Perico N, J Chromatographic Science, 2008, 46(6), 485-489.

9. Seshachalam U, Rao Narasimha D V L, Haribabu B and Chandrasekhar K B, Chromatographia, 2007, 65(5/6), 355-358. 


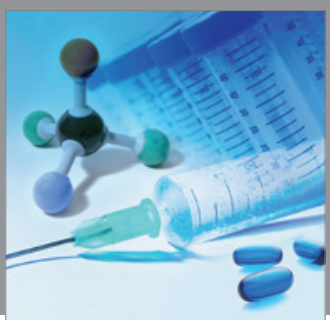

International Journal of

Medicinal Chemistry

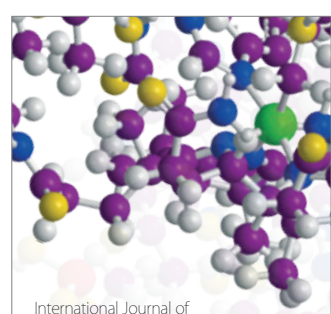

Carbohydrate Chemistry

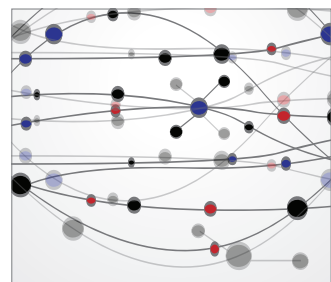

The Scientific World Journal
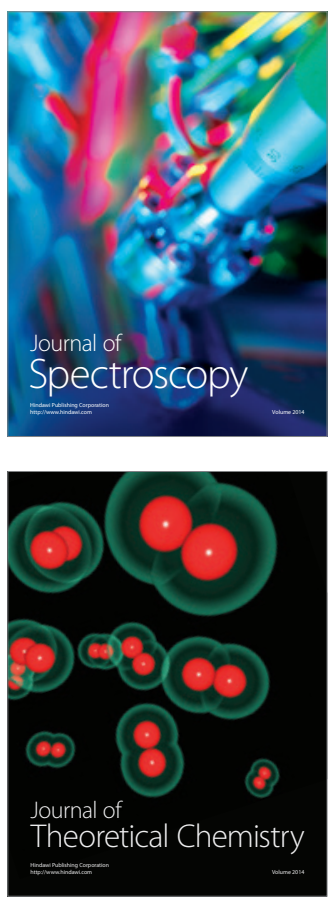
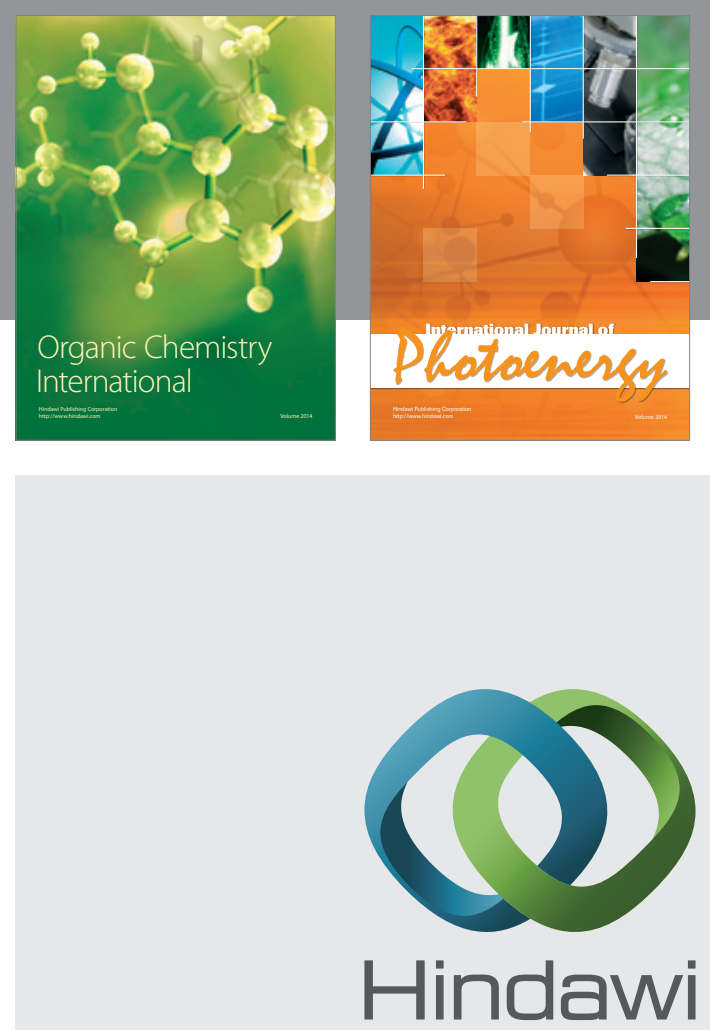

Submit your manuscripts at

http://www.hindawi.com
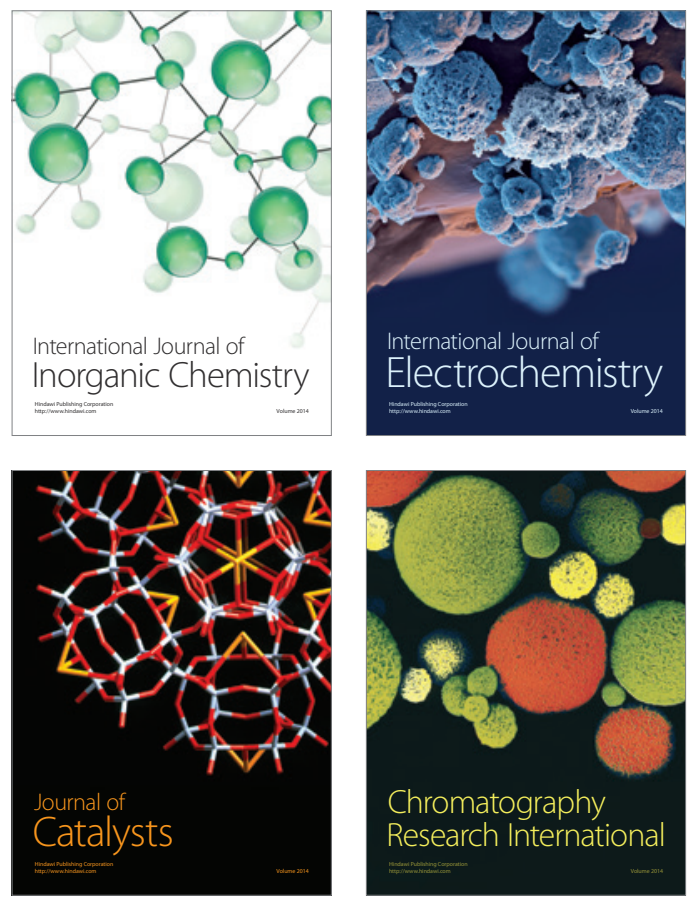
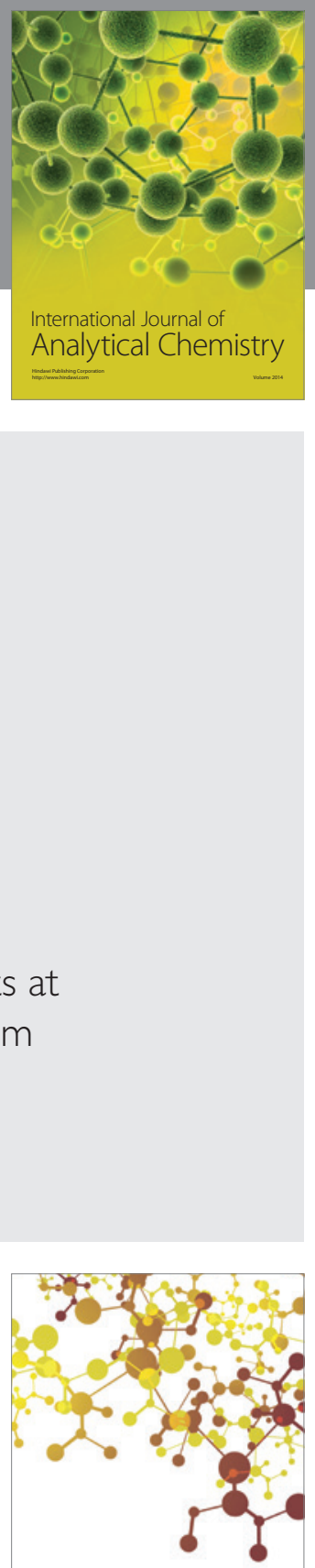

Journal of

Applied Chemistry
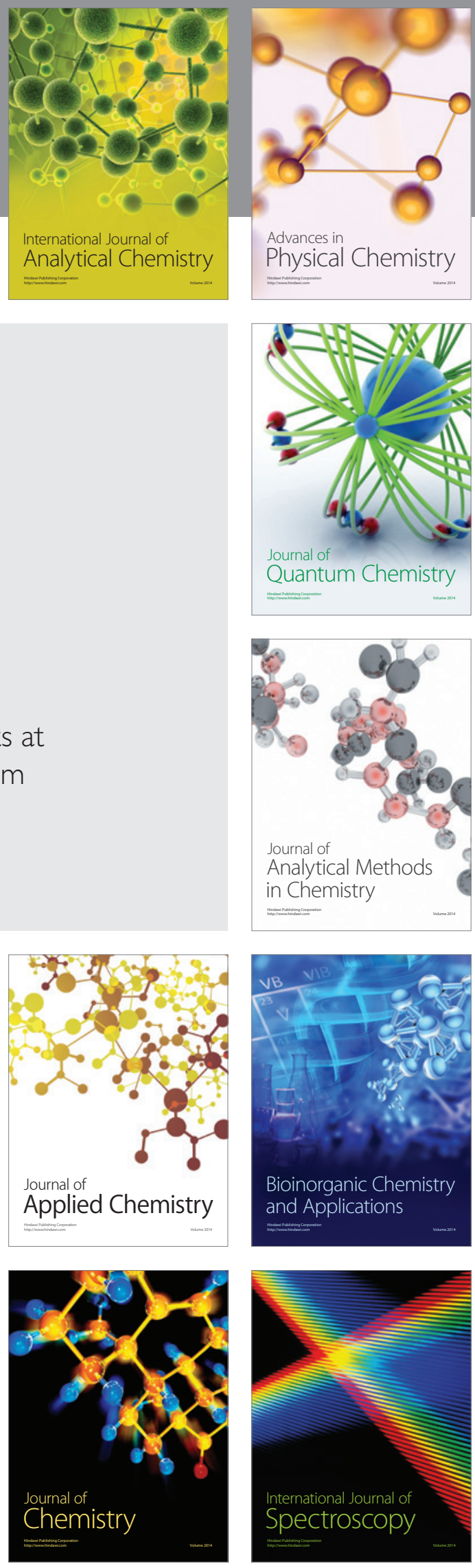